\title{
A GENÈVE
}

\section{Décès de M. Carl J. Burckhardt, membre honoraire du CICR}

C'est avec douleur que le Comité international a appris le décès, survenu le 3 mars 1974, de M. Carl J. Burckhardt. Nommé membre de l'institution en 1933, M. Burckhardt ne cessa d'agir aux côtés de cette autre éminente personnalité et ancien président du CICR que fut Max Huber. Dès novembre 1939, il se consacra entièrement aux tâches du Comité international. C'est au cours de la seconde guerre mondiale qu'il donna toute sa mesure.

Il fallait un homme qui vit grand et loin. Il fut cet organisateur et diplomate fort et clairvoyant auquel d'innombrables êtres humains doivent d'avoir survécu à leurs blessures et à l'emprisonnement, ou encore d'avoir échappé à la mort par la faim.

Il présida, tout d'abord, la Division chargée des envois de secours aux prisonniers de guerre et internés civils, puis la Commission mixte de secours à laquelle incomba, au sein des institutions internationales de la Croix-Rouge, l'assistance aux populations civiles. On créa une flotte de 40 navires pour transporter ces secours, sous la protection du signe de la croix rouge, à travers les mers infestées de sous-marins. C'est M. Burckhardt encore qui obtint que soit allégé le blocus allié en faveur des populations civiles des pays dévastés par la guerre et qui souffraient de la famine. Il prit une très large part aux négociations, longues et difficiles, qu'il fallut poursuivre et ce fut lui qui négocia les accords qui permirent d'organiser, en Grèce, pendant la durée de l'occupation, une assistance régulière à plus d'un million de personnes. 
Cette œuvre de secours fut d'une très grande ampleur, mais elle alla de pair avec celle qui fut menée pour la protection des victimes de la guerre, en veillant notamment à l'observation des Conventions de Genève. Certaines démarches qu'entreprit $M$. Carl Burckhardt furent d'une signification capitale et apparaissent, avec le recul du temps, comme un témoignage de la victoire remportée, si tardive soit-elle, sur les forces de destruction. En particulier, son intervention à la fin de la guerre lorsqu'il se rendit personnellement auprès de dirigeants du III ${ }^{e}$ Reich et leur arracha des concessions en faveur des déportés politiques.

Toujours il eut le sentiment de sa responsabilité à l'égard de l'institution et, à travers elle, envers tous ceux qui souffrent. Elu président, en décembre 1944, il eut cette phrase qui caractérise et éclaire la valeur de son engagement: " Nous sommes tenus, en y mettant le meilleur de nous-mêmes, à jouer notre rôle dans cette course au flambeau où, devant la grande nuit qui monte, nous devons veiller sur la flamme et la transmettre. " Il cessa d'exercer la fonction présidentielle quelques mois plus tard, et conserva, jusqu'en 1948, le titre de "président en congé ".

A l'occasion de son $70^{\mathrm{e}}$ anniversaire, en 1961, le CICR lui décerna sa médaille d'or. En 1965, il demanda à être relevé de ses fonctions, et il fut nommé membre honoraire.

M. Carl J. Burckhardt trouva pleinement à exercer, dans l'œuvre de la Croix-Rouge, un sens de l'humanisme actif, une haute et vaste intelligence qui lui faisaient sentir d'emblée l'essentiel. Si la Croix-Rouge lui permit d'être lui-même dans une tâche pratique, elle lui doit plus encore pour le dévouement qu'il manifesta et le service exemplaire qu'il rendit à l'idéal humanitaire. Le Comité international lui gardera un souvenir profondément fidèle et reconnaissant. 